\title{
Conceito Skinneriano de Comportamento Eficaz
}

\author{
Ieda Maria Bertola Mazzo \\ Maura Alves Nunes Gongora \\ Universidade Estadual de Londrina
}

\begin{abstract}
RESUMO
Este ensaio apresenta o resultado de um exame de textos skinnerianos, conduzido com o objetivo de explicitar critérios com os quais Skinner emprega o termo eficaz para qualificar comportamentos. Foram examinados alguns textos nos quais ele mais emprega esse termo: aqueles que tratam das contingências de reforço, do planejamento de contingências e da sobrevivência das culturas. Verificou-se que Skinner tende a usar a expressão "comportamento eficaz" em relação a dois temas: 1- possibilidades ou chances de reforço e 2- comportamento cultural e sobrevivência de culturas. No primeiro caso, ele usa o termo para qualificar: respostas operantes, classes de respostas operantes específicas e repertório comportamental especial, que demonstrem maior probabilidade de produzir consequências ambientais reforçadoras. No segundo caso, o autor denomina eficaz ao comportamento que produz, não apenas consequências reforçadoras, mas também consequências culturais relevantes. Verificou-se, ainda, que os critérios aqui explicitados constituem parte dos argumentos com os quais Skinner defende o planejamento de contingências como uma forma de garantir o aprendizado de comportamento humano eficaz.
\end{abstract}

Palavras-chave: B. F. Skinner; comportamento eficaz; chances de reforço; comportamento cultural.

\begin{abstract}
Skinner's Concept of Efficient Behavior

This essay presents the results of an analysis of Skinnerian texts, developed with the aim of making explicit the criteria with which Skinner uses the term efficient to qualify behaviors. Some texts in which he uses this term were examined: those that deal with reinforcement contingencies, contingency planning and cultures' survival. It was verified that Skinner tended to use the expression "efficient behavior" in reference to two themes: 1 - possibilities or chances of reinforcement and 2 - cultural behavior and cultural survival. In the first case, he uses the term to qualify: operant responses, specific operant response classes and special behavior repertoire that present more probability of producing environmental reinforcing consequences. In the second case, efficient behavior not only produces reinforcing consequences, but also socially relevant cultural consequences. It was observed that the criteria made explicit here constitute part of the arguments with which Skinner defends contingency planning as the one way of assuring the learning of efficient human behavior.
\end{abstract}

Keywords: B. F. Skinner; efficient behavior; reinforcement chances; cultural behavior.

Ao tratar de certos temas em suas análises comportamentais, B. F. Skinner refere-se ao comportamento humano por meio de adjetivos tais como: útil, produtivo, eficiente ou eficaz. O uso desses termos adjetivos para qualificar comportamentos, além de frequente, por vezes, constitui expressões marcantes em alguns de seus textos. Por exemplo, as expressões - comportamento eficaz, comportamento útil, comportamento apropriado, comportamento produtivo, etc. Essas expressões são adotadas em pertinentes considerações do autor acerca do comportamento humano, sendo mais constantes nas descrições dos efeitos de contingências de reforço (Skinner, 1969b; 1972/1975a; 1989c; 1971/2002) e nas discussões sobre tecnologia do comportamento (Skinner, 1969a, 1972/1975b, 1972/1975d, 1971/2002). Em Skinner (1972/1975b), por exemplo, a defesa de uma tecnologia do ensino vem acompanhada, de modo insistente, pelo argumento de que tal tecnologia viabilizaria o ensino de comportamentos de qualidade.

Entretanto, apesar do patente interesse do autor pela qualidade do comportamento, verificou-se que ele não costuma explicitar, em suas análises comportamentais, o sentido por ele atribuído àquelas expres- 
sões qualificadoras do comportamento. Isto quer dizer que uma compreensão criteriosa dos diferentes sentidos com os quais o autor emprega tais termos ou expressões dependeria de um exame de seus textos, conduzido especialmente com essa finalidade. Neste ensaio, pretende-se apresentar um exame desse tipo. Procura-se explicitar aqui alguns dos critérios com os quais o autor costuma qualificar comportamentos como eficaz ou eficiente, útil, produtivo, apropriado e assim por diante.

O interesse em estudar as qualificações acima, empregadas por Skinner, deveu-se, entre outros motivos, à possibilidade de se encontrar, através da compreensão dos usos desses adjetivos, um caminho para se estudar formas de vinculação do behaviorismo radical com o pragmatismo. Isto, tendo em conta que o adjetivo eficaz, um dos mais usados, poderia ter um sentido aproximado ao de critério de verdade como efetividade, adotado em várias modalidades de pragmatismo. A possibilidade de vinculação do behaviorismo skinneriano com o pragmatismo, embora polêmica, tem sido sugerida e defendida com argumentação consistente, por um grande número de autores: Abib (2001), Baum (1999), Guilhardi (1995), Lattal e Laipple (2003), Lopes (2007), Tourinho e Neno (2003), Zuriff (1985), entre outros. Podem ser citados, ainda, outros autores denominados contextualistas que, no entanto, compartilham vários pressupostos do pragmatismo, por exemplo, Carrara (2001), Hayes, Hayes, Reese e Sarbin (1993) e Morris (1988).

A alta frequência de uso de adjetivos ao referir-se ao comportamento, mostrava também, uma possível preocupação de Skinner com a qualidade do comportamento, ou seja, com o seu valor. Neste caso, estudar tais adjetivos poderia ser uma forma de contribuir com a compreensão do sistema ético skinneriano. Cabe pontuar que os próprios pressupostos pragmatistas já podem implicar preocupação ética (Abib, 2001). Isto só reforçou, ainda mais, a hipótese de vinculação dos usos skinnerianos dos adjetivos com pressupostos do pragmatismo. Relacionados ou não com o pragmatismo, o sistema ético skinneriano tem sido tratado por diferentes autores: Abib (2007), Baum (1999), Carrara (2000), Castro e de Rose (2008), Dittrich e Abib (2004), Holland (1978) e Michael (1977), entre outros.

Voltando aos objetivos deste ensaio, é importante esclarecer que não se pretende apresentar aqui algum tipo de análise do behaviorismo skinneriano sob a ótica pragmatista. A digressão acima teve apenas o objetivo de mostrar que a análise dos usos de termos adjetivos, aqui proposta, pode ser pertinente e rele- vante para complementar outros estudos do sistema teórico skinneriano, entre os quais se destacam as possibilidades de estudos na ótica do pragmatismo e da ética. $\mathrm{O}$ estudo aqui relatado foi conduzido na forma de um exame intratexto, no qual se procura examinar os critérios skinnerianos para o uso do termo eficaz, perseguindo, antes de tudo, a compreensão de sua concepção de comportamento eficaz. Como se trata de análise intratexto, busca-se compreender a concepção skinneriana de comportamento eficaz, à luz do próprio modelo teórico com o qual Skinner explica o comportamento: o modelo de variação e seleção pelas consequências.

Ao conduzir o exame das qualificações atribuídas por Skinner ao comportamento, pode-se verificar que, para o autor, a palavra eficaz pode sintetizar as demais qualificações não só para o comportamento, mas também para o indivíduo como um todo:

Um ponto importante é que contingências efetivas precisam ser programadas - isto é, elas são efetivas apenas quando a pessoa passou por uma série de contingências intermediárias. Aqueles indivíduos que alcançam contingências terminais serão produtivos, úteis, criativos e felizes - em uma palavra, eficazes ao máximo [itálicos nossos] (Skinner, 1969a, pp. 39-40).

Neste ensaio será adotada e examinada apenas a expressão - comportamento eficaz. Com isto, além de seguir uma tendência do próprio Skinner, procura-se evitar repetições desnecessárias e outras dificuldades e confusões que poderiam advir do exame concomitante de muitos dos adjetivos empregados por ele.

A análise aqui conduzida orienta-se por dois temas gerais, em torno dos quais vai se desdobrando o exame que explicita critérios com os quais o autor usa a expressão - comportamento eficaz. Os temas são: 1possibilidades ou chances de reforço e 2- comportamento cultural e sobrevivência de culturas. Explicitar tais critérios foi o caminho escolhido para se buscar, de fato, diferentes sentidos com os quais Skinner emprega o termo eficaz para qualificar comportamento. São explicitados alguns sentidos distintos que, ao final da análise, permitem alguma compreensão da concepção skinneriana de comportamento eficaz.

\section{POSSIBILIDADES OU CHANCES DE REFORÇO}

As possibilidades ou chances de reforço referem-se, em primeiro lugar, às consequências de respostas que aumentam sua probabilidade de ocorrência. Se as modificações ambientais produzidas por determinada 
resposta afetarem diretamente sua probabilidade de ocorrência, então, pode-se considerar que estas modificações funcionaram como consequências reforçadoras para o comportamento, uma vez que entraram em relação funcional com aquela classe de respostas (Baum, 1999; Catania, 1999; Millenson, 1967/1975; Skinner 1953/1998). Neste ponto, examina-se uma das dimensões das contingências operantes na qual se entende que o comportamento pode ser fortalecido pela própria alteração ambiental que produz. Cabe ressaltar que Skinner não define um comportamento operante pelas mudanças ambientais que produz até porque, como pontua Abib (2007) o comportamento filogenético e o cultural também produzem mudanças ambientais. A diferença é que o operante pode ser fortalecido pelo efeito estimulacional (hedônico) tanto das mudanças que produz, quanto de outras consequências imediatas, devido à sensibilidade evoluída da espécie humana às consequências imediatas. No entanto, será visto mais adiante que Skinner costuma qualificar como eficaz aqueles comportamentos operantes nos quais se verifica que foram as respostas que produziram as mudanças ambientais (consequências) reforçadoras.

De acordo com Millenson (1967/1975), em termos operacionais, as consequências reforçadoras podem ocorrer de duas formas: pela produção de estímulos (no reforçamento positivo) e pela remoção de estímulos (no reforçamento negativo). Nas análises dos textos skinnerianos, verificou-se que ele pode denominar eficaz tanto aos comportamentos reforçados positivamente quanto aos reforçados negativamente, pois o que ele leva em conta é o fato do comportamento ser fortalecido pelas suas próprias consequências ambientais. Segue uma ilustração da ênfase skinneriana sobre as consequências reforçadoras que implicam mudanças ambientais: "Os homens agem sobre o mundo e modificam-no, e por sua vez, são modificados pelas consequências de sua ação (Skinner, 1957, p. 1).

Contudo, observa-se que nem todas as modificações ambientais produzidas por determinadas respostas acabam por afetar apenas sua própria probabilidade de ocorrência. Certas modificações, produzidas por um comportamento específico, podem participar do processo de fortalecimento de um outro comportamento. Por exemplo, um comportamento pode estabelecer a ocasião para que as consequências de respostas que fazem parte de outro comportamento (do mesmo indivíduo) possam apresentar função reforçadora. Neste caso, consequências reforçadoras são pro- duzidas de maneira indireta pelas modificações ambientais promovidas por respostas que antecedem o comportamento que está sendo reforçado. Um processo desse tipo pode ser exemplificado nesta citação:

\begin{abstract}
Deparando com uma situação para a qual não há comportamento eficiente disponível (na qual não podemos emitir uma resposta que seja provavelmente reforçada), comportamo-nos de outras maneiras que tornam possível o comportamento eficiente (melhoramos nossas chances de reforço) (Skinner, 1972/1975b, p.114).
\end{abstract}

Desta forma, com base nas palavras do autor, entende-se que comportamento eficaz pode se referir aos comportamentos que promovem condições ambientais que aumentem a probabilidade de outro comportamento ser reforçado ("comportamo-nos de outras maneiras que tornam possível o comportamento eficiente", p. 114). Verifica-se aqui, que comportamento eficaz (ou eficiente) alude tanto aos comportamentos diretamente reforçados, bem como a outros comportamentos que contribuem para que um comportamento específico seja reforçado.

Se, a princípio, comportamento eficaz pode ser entendido como um conjunto de respostas que torna o indivíduo mais apto a lidar com as adversidades do seu ambiente, como indica a última citação, então, há que se considerar, especificamente, que o indivíduo torna-se mais apto na medida em que aumentam suas chances ou possibilidades de reforço. Assim, nesta análise, pode-se considerar que o pressuposto de "possibilidades ou chances de reforço" está diretamente implicado na compreensão do conceito skinneriano de comportamento humano eficaz.

Até o momento, foram pontuados dois processos que favorecem as chances de reforço (respostas reforçadas diretamente e respostas reforçadas indiretamente). Para esclarecer tais processos, é preciso introduzir, na discussão, os conceitos de classe de respostas e de repertório comportamental. De acordo com Skinner (1972/1975c; 1953/1998), possibilidades ou chances de ocorrer reforço podem ser examinadas de duas maneiras: (1) uma que as enfoca como efeitos produzidos por uma classe de respostas e (2) outra que as analisa como resultados do repertório comportamental, referindo-se ao funcionamento do indivíduo como um todo. Ambas auxiliam na compreensão conceitual de comportamento eficaz. Ou seja, nos dois casos, o comportamento pode ser considerado mais ou menos eficaz na medida em que aumentam ou diminuem suas chances de reforço. 


\section{Possibilidades ou chances de reforço demonstradas por uma classe de respostas}

De acordo com Millenson (1967/1975), o comportamento operante como objeto de estudo implica algumas dificuldades técnicas para a ciência que se propõe a estudá-lo. Primeiramente, isto ocorre pela própria natureza do objeto de estudo, uma vez que o comportamento não é passível de ser apreendido (imobilizado), como outros objetos tais como o corpo humano, ondas elétricas, entre outros. Essas peculiaridades do comportamento estão claramente pontuadas por Skinner (1953/1998), quando ele ressalta a dificuldade de estudo imposta pela própria natureza do comportamento, na seguinte explanação:

O comportamento é uma matéria difícil, não por ser inacessível, mas porque é extremamente complexo. Desde que é um processo, e não uma coisa, não pode ser facilmente imobilizado para observação. É mutável, fluido e evanescente, e, por esta razão, faz grandes exigências técnicas da engenhosidade e energia do cientista. Contudo, não há nada essencialmente insolúvel nos problemas que surgem deste fato (Skinner, 1953/1998, p.16).

As dificuldades metodológicas advindas da concepção do comportamento como processo contínuo têm sido resolvidas descrevendo-o em unidades menores denominadas respostas. O conceito de resposta e de classes de resposta facilita a compreensão do comportamento enquanto fluxo de inter-relações entre organismo e ambiente. Assim, o comportamento pode ser entendido como a ocorrência de determinadas respostas do organismo que se dão em inter-relação com o ambiente, ao longo de um dado período de tempo. Quando certas respostas modificam o ambiente produzindo um efeito comum e, parte delas passa a ficar sob controle deste efeito ambiental, torna-se possível a reprodução do comportamento. Segundo Millenson (1967/1975) e Catania (1999), considera-se que as respostas controladas por um efeito comum constituem uma classe de respostas. Neste caso, o critério funcional é utilizado para a especificação de quais respostas constituem uma certa classe. Na Análise do Comportamento, o critério funcional é um dos mais utilizados para se definir classe de respostas.

Na visão de Baum (1999) e de Millenson (1967/ 1975), um comportamento repetido nunca é igual à primeira ocorrência, ou seja, o efeito do ambiente retroage ao organismo, afetando apenas algumas das respostas que constituíram aquele comportamento. Pelo fato de o comportamento ser um processo, o que é reproduzido são instâncias do comportamento, ou melhor, parte das respostas de uma classe e não a sua totalidade, uma vez que podem ser observadas diferenças topográficas nas respostas reproduzidas. Desse modo, analistas do comportamento entendem que um comportamento operante não se define por sua morfologia, mas por uma "classe de respostas que produzem o mesmo efeito sobre o ambiente [itálicos nossos]" (Baum, 1999, p. 95).

Deve-se levar em conta que, ao longo do tempo, as consequências ambientais produzidas por uma classe de respostas podem ser mais ou menos reforçadoras, e, ainda mais, podem vir a enfraquecer um dado comportamento. Nesta análise, as possibilidades ou chances de reforço referem-se às consequências no ambiente, diretamente promovidas por uma classe de respostas, cujo efeito é potencialmente fortalecedor. Portanto, comportamento eficaz pode ser considerado como um conjunto (classe) de respostas que produz consequências com função reforçadora em um dado ambiente, pois aumentam sua probabilidade de ocorrência. Com isso, nessa primeira análise sobre as possibilidades ou chances de ocorrer reforço, fica explicitado o "primeiro critério específico" com o qual Skinner emprega o termo eficaz para qualificar comportamento: é quando ele se refere a uma classe de respostas que produz consequências reforçadoras.

Como assinalado anteriormente, uma classe de respostas pode ter sua probabilidade maximizada em decorrência de condições ambientais produzidas por outras classes de respostas. Neste caso, Skinner (1953/1998; 1972/1975b) afirma que os reforçadores para um comportamento são promovidos de maneira indireta por outros comportamentos de um mesmo indivíduo. Neste ponto, é preciso recorrer à noção skinneriana de "repertório comportamental" para podermos avançar no entendimento da expressão comportamento eficaz.

\section{Possibilidades ou chances de reforço demonstradas por repertório comportamental}

Sob o enfoque de repertório comportamental, as chances de reforço são estudadas como efeitos ambientais produzidos por diferentes classes de respostas de uma mesma pessoa, ou seja, as possibilidades de ocorrer reforço resultam do repertório total de comportamentos de um indivíduo. Neste caso, o estudo das chances de reforço não se limita à análise do efeito direto de uma dada classe de respostas. Mas, enfoca a produção de alterações ambientais, promovidas por 
diferentes classes de respostas do mesmo indivíduo, que provavelmente aumentem a probabilidade geral de consequências reforçadoras ocorrerem. Isto quer dizer que a partir daqui, as chances de reforço serão examinadas, também, como resultado do funcionamento do repertório global do indivíduo.

Para Skinner (1974), repertório comportamental alude a diferentes comportamentos resultantes de uma história de relações que o indivíduo estabeleceu com as diferentes instâncias de seu ambiente, ao longo de toda sua vida. O repertório de comportamentos de um indivíduo é resultado de um longo processo de condicionamento, operante e respondente, promovido pelo arranjo de condições ambientais constituídas por diferentes contingências de reforço.

Nesse processo, tende a ocorrer múltiplos e variados arranjos de contingências ambientais o que implica múltiplas e variadas inter-relações estabelecidas entre o indivíduo e seu ambiente. O que acontece é que as consequências de alguns desses arranjos passam a exercer maior controle sobre o comportamento do indivíduo, selecionando determinados comportamentos. Ao longo do tempo, com a ação seletiva do ambiente, através de processos de condicionamento e de extinção, diferentes comportamentos são fortalecidos, enquanto outros são extintos. Além disso, alguns comportamentos são mantidos em esquemas intermitentes e outros em esquemas contínuos de reforço, de forma que o controle do comportamento determinado por diferentes contingências de reforço vai se fazendo novo constantemente, tendo em vista que as condições ambientais são alteradas continuamente.

Uma vez que o processo de transformação do repertório de cada indivíduo é contínuo, seria importante, na visão skinneriana, que na educação de crianças e jovens, fossem modelados comportamentos capazes de produzir mudanças ambientais relevantes, ou seja, comportamentos transformadores do ambiente. Por exemplo, os comportamentos de resolver problemas, de tomada de decisão e o de autocontrole (Skinner, 1972/1975, 1971/2002). Nessa perspectiva, o repertório de um indivíduo é considerado eficaz se, entre as alterações ambientais que promove no ambiente, predominam aquelas condições ambientais que potencializam a probabilidade geral de ocorrer reforço. Ou seja, tal repertório favorece as chances de ocorrer um maior número de classes de repostas com probabilidade de serem reforçadas, do que de classes de repostas com probabilidade de serem enfraquecidas ou extintas.
Do exposto nesta seção, já se pode concluir que para se compreender o sentido de repertório eficaz, a produção de reforçadores prevalece como uma condição imprescindível, porém, não somente como o efeito de uma classe de respostas. Aqui, as possibilidades ou chances de reforços dizem respeito ao arranjo e rearranjo das consequências produzidas pela variabilidade comportamental, ou seja, pela diversidade de classes de resposta que uma pessoa pode apresentar. E ainda mais, as chances de reforço são determinadas pelo conjunto de modificações ambientais produzidas pelo indivíduo através de suas próprias ações sobre o ambiente. Modificações estas que se complementam e se renovam ao longo do tempo, maximizando e mantendo as chances de reforço para diferentes comportamentos potenciais. Neste ponto, pode-se compreender melhor as frequentes defesas feitas por Skinner no livro Tecnologia do Ensino $(1972 / 1975)$ a respeito da variabilidade comportamental, pois, ela favoreceria imensamente as chances de reforço, constituindo assim uma qualidade essencial do repertório eficaz.

Com o foco da análise sobre o repertório comportamental, identifica-se mais um sentido para a expressão - comportamento eficaz. Além do efeito direto produzido por uma dada classe de respostas, também são examinadas as alterações ambientais que afetam indiretamente a probabilidade de que respostas de uma dada classe voltem a ocorrer. Ou seja, trata-se aqui da possibilidade de uma dada classe de respostas produzir alterações ambientais que potencializem as chances de reforço para outras classes de resposta, do mesmo indivíduo. Conclui-se, assim, o exame de mais um critério para o uso skinneriano do termo eficaz. Com esse segundo critério, comportamento eficaz pode ser entendido como o repertório de comportamentos de um indivíduo, que modifica o ambiente produzindo, predominantemente, condições ambientais com função potencialmente reforçadora para os comportamentos do próprio indivíduo.

Complementando o exame do conceito de repertório, é importante considerar que o processo de condicionamento que determina os comportamentos que constituirão o repertório de um indivíduo se dá de maneira particular para cada pessoa, apesar da atuante determinação das contingências culturais. Sobre isso, o autor faz a seguinte consideração:

Ainda assim, o indivíduo é quando muito um ponto no qual muitas linhas de desenvolvimento se reúnem. Sua individualidade é inquestionável. Cada célula em seu corpo é produto genético único, tão 
único como a clássica marca da individualidade, a impressão digital. E mesmo dentro da cultura mais uniforme, cada história pessoal é única. Nenhuma cultura pode, intencionalmente, destruir tal unicidade, e como vimos, qualquer esforço neste sentido constitui um mau planejamento (Skinner, 1971/2002, p. 209).

Ao examinar as chances de reforço na perspectiva de repertório comportamental, além do sentido de comportamento eficaz poder ser interpretado como repertório eficaz, pode-se interpretar ainda, que isto implica um indivíduo ou uma pessoa eficaz. Esta interpretação parece plausível, ao menos por dois motivos: primeiro, porque o uso aqui examinado do termo diz respeito à totalidade dos comportamentos potenciais que um indivíduo pode vir a apresentar, em quaisquer dos ambientes com os quais há probabilidade dele vir a relacionar-se; segundo, porque o uso do termo aqui examinado inclui a possibilidade de partes do repertório de um indivíduo participarem, indiretamente, do fortalecimento de outras partes do repertório deste mesmo indivíduo. Pode-se assim concluir que, neste caso, quando Skinner se refere ao comportamento com o qualificativo eficaz, ele deve, em geral, estar se referindo ao comportamento como um todo e, assim, deve considerar que a pessoa é eficaz ao lidar com o mundo que a cerca. Além disso, Skinner (1987b) afirma, textualmente, que o repertório ontogenético constitui aquilo que os outros veem e que denominamos pessoa.

Nosso exame conduzido até aqui vem demonstrando a complexidade da teoria operante do comportamento. É uma teoria que permite investigar muitos outros critérios para a concepção skinneriana de repertório eficaz. No entanto, neste ensaio, nos limitaremos apenas à análise operante relativa ao critério das chances de reforço com dois possíveis desdobramentos. $\mathrm{O}$ primeiro deles refere-se à noção skinneriana de "pessoa" que acabamos de assinalar. Um segundo desdobramento possível, consiste em admitir que a concepção de repertório eficaz, com base em suas chances de reforço, expressa, ao menos em parte, a visão skinneriana de homem. Visão na qual o homem pode ser educado para ser mais ou menos eficaz, ou seja, para agir mais ou menos ativamente sobre o ambiente, alterando-o a seu favor (Skinner, 1972/1975d; 1971/2002).

Continuando, Skinner (1989d) afirma que grande parte dos comportamentos complexos que constituem repertórios comportamentais é determinada por contingências sociais, ou, nos termos dele, culturais. Em vista disso, aspectos relacionados à vida do indivíduo em grupo, também deveriam ser considerados para uma melhor compreensão dos escritos skinnerianos a respeito de comportamento eficaz. Tendo isso em conta, o próximo passo será, então, deslocar a presente análise do domínio individual para o domínio das práticas culturais.

\section{COMPORTAMENTO CULTURALMENTE EFICAZ}

Sobre a participação das contingências sociais na determinação do repertório comportamental, o autor faz as seguintes considerações:

O comportamento também passou a ser parte do escopo de uma análise científica. Ele é produto de três tipos de seleção, a primeira delas, a seleção natural, é o campo da etologia. A segunda, o condicionamento operante, é o campo da Análise do Comportamento. A terceira, a evolução das contingências sociais de reforço, que denominamos culturas, explica os amplos repertórios de comportamentos característicos da espécie humana [itálicos nossos] (Skinner, 1989d, p. 27).

No entanto, Skinner (1989b) pontua que na noção de repertório comportamental, o foco de análise das consequências reforçadoras está restrito aos comportamentos do indivíduo. Dessa forma, o sentido de repertório eficaz pautado no exame das chances de reforço, restringe-se às consequências reforçadoras para as respostas do próprio indivíduo, não incluindo, a princípio, as implicações dessas consequências para o seu grupo social.

Além disso, Skinner (1987b) ressalta que contingências culturais selecionam comportamentos originariamente individuais, mas que de alguma maneira contribuem para resolver problemas do grupo. No entanto, nem sempre os comportamentos assim selecionados implicam consequências reforçadoras para o indivíduo. Dessa maneira, se o repertório comportamental é, em parte, determinado por contingências culturais, então, um repertório eficaz não poderia se limitar apenas ao efeito reforçador para comportamentos do próprio indivíduo, uma vez que contingências culturais podem não ser reforçadoras.

Segundo Skinner (1987b), contingências de seleção ontogenética e cultural selecionam comportamentos distintos. Contingências ontogenéticas selecionam comportamento respondente (condicionado) e operante. A seleção de operantes, que ocorre por condicionamento operante, é uma possibilidade decorrente da suscetibilidade do organismo às consequências imedia- 
tas de seu comportamento. Afirmar que uma contingência é reforçadora implica que as consequências que seguem classes de respostas podem afetar a sua probabilidade de ocorrência, aumentando-a ou reduzindo-a. Segundo Baum (1999) e Millenson (1975), quando o efeito é o aumento da frequência de respostas, a consequência exerceu função reforçadora e, com isso, um comportamento operante foi selecionado.

No domínio cultural, o que é selecionado também é o comportamento de indivíduos. Porém, os comportamentos culturalmente selecionados devem apresentar consequências que afetam o grupo ao qual o indivíduo pertence. Para Skinner (1987b) são os efeitos sobre o grupo e não os efeitos reforçadores para comportamentos individuais de seus membros, que são responsáveis pela evolução da cultura. Como as consequências culturais não afetam, de maneira imediata, o comportamento do indivíduo, ou seja, sua ação é atrasada [até o ponto de ultrapassar o tempo de vida do indivíduo], elas não podem ter função reforçadora, isto é, não podem retroagir diretamente sobre o comportamento do indivíduo.

Assim, no estudo de contingências culturais pode-se considerar que a direção do reforço é invertida, ou seja, o efeito primeiro do comportamento deve ser para o grupo ao qual o indivíduo pertença e não para o comportamento do indivíduo, como retratado por Skinner (1989a) nesse exemplo:

Ao demonstrar que sentimos prazer quando uma pessoa se une a nós, nós reforçamos a união. A direção do reforçamento é invertida. Não é o nosso comportamento, mas o comportamento daquele que amamos que é reforçado. O efeito primeiro é sobre o grupo. Ao demonstrar que sentimos prazer pelo que a outra pessoa fez, nós reforçamos o fazer, e desse modo fortalecemos o grupo (p. 6).

Mas, para que a inversão seja estabelecida a consequência cultural deve suplantar o efeito imediato das consequências reforçadoras, ao qual o comportamento operante é suscetível. A sensibilidade às consequências imediatas interfere no controle que consequências postergadas possam exercer sobre o comportamento do indivíduo, uma vez que o efeito primeiro destas deve ser para o grupo. Para tanto, o indivíduo não poderia estar susceptível às consequências imediatas de seu comportamento. Diante disso, Skinner (1989a) apresenta algumas indagações pertinentes:

Podemos agir no sentido de agradar um amante, porque assim nosso próprio prazer é aumentado, mas por que deveríamos fazê-lo quando isso não ocorre? Podemos promover obras de Brahms ou ajudar a salvar Veneza, por que assim temos mais oportunidades de desfrutá-los, mas por que haveremos de fazê-lo quando não for este o caso? (p. 6)

Ao discutir algumas implicações das contingências de reforço, Skinner (1987a) afirma que o descompasso temporal, entre consequências reforçadoras (imediatas) e culturais (atrasadas) no controle do comportamento, pode tornar-se conflitante em duas direções: quando o comportamento sob controle reforçador (para o indivíduo) não favorece o grupo e quando um comportamento relevante para o grupo não é reforçador para o indivíduo. Por exemplo, usar drogas é consequenciado por sensações fisiológicas de prazer, possivelmente reforçadoras para o indivíduo. Contudo, para o grupo, o uso de drogas pode ter um efeito desastroso. Entre outras coisas, o usuário tende a não participar das soluções dos problemas do grupo, comportar-se de maneira agressiva e gastar dinheiro público com uma possível recuperação. Nesse sentido, o comportamento de usar drogas não é um comportamento que auxilia o grupo a solucionar seus problemas, não constituindo uma prática relevante para o grupo, porém, produz efeitos reforçadores (individuais) que o mantém.

Em outros casos, os efeitos danosos das relações reforçadoras são tão retardados que possivelmente afetarão apenas comportamentos de indivíduos que viverão em gerações posteriores, como visto nas agressões realizadas à natureza. Por exemplo, quando não são empregados meios de reciclar os materiais plásticos utilizados no dia a dia, com medidas simples tais como a separação do lixo, exige-se que novos materiais plásticos sejam produzidos, diminuindo cada vez mais as reservas de matéria prima utilizada (petróleo, por exemplo). A baixa frequência de repostas de separar o lixo pode poupar o tempo (efeito reforçador) de quem não o separa, mas também não permite que a natureza reponha suas reservas de matéria em tempo hábil. Consequentemente, a escassez de matéria-prima poderá torna-se uma realidade para futuras gerações. Um exemplo desse tipo é a redução já observada nos mananciais de água como consequência do uso inadequado do solo. Escassez grave de água já afeta algumas regiões do mundo. Sobre o último exemplo, cabe um esclarecimento: a preocupação de Skinner com as consequências culturais e com a sobrevivência das culturas não se limita ao efeito do comportamento para pequenos grupos, ele, de fato, se preocupa com as consequências do comportamento 
humano que podem afetar o bem estar da coletividade (ou da humanidade) em geral.

Além do conflito entre indivíduo e coletividade, Skinner (1987a) também frisa que a sensibilidade às consequências imediatas, reforçadoras, pode prejudicar o próprio indivíduo. Exemplificando: comer compulsivamente, embora produza reforçadores imediatos, em longo prazo pode gerar consequências punitivas para a própria pessoa (doenças, sofrer discriminação social pela obesidade, etc).

A esta altura, parece ir ficando claro que se a análise de repertório eficaz ficasse restrita apenas ao nível ontogenético, ela seria incompleta porque deixaria de considerar que certos comportamentos que produzem consequências reforçadoras para o comportamento do próprio indivíduo podem vir a tornar-se ineficazes ou prejudiciais. Podem, em longo prazo, trazer prejuízos tanto para o próprio indivíduo, quanto para seu grupo, bem como para indivíduos de futuras gerações. Isto quer dizer que sua eficácia estaria confinada apenas ao efeito reforçador, em curto prazo, para o próprio indivíduo.

Skinner mostrou, em vários de seus textos, preocupação com os prejuízos resultantes das consequências reforçadoras, devido ao seu caráter imediato. Em vista dessa preocupação, a ideia de planejar contingências, defendida por Skinner (1972/1975d, 1948/1975e), constitui uma tentativa de elaborar e de aplicar uma tecnologia comportamental, capaz de minimizar efeitos danosos de reforçadores imediatos que controlam o comportamento operante. Para ele, contingências deveriam ser planejadas essencialmente com o objetivo de favorecer o controle do comportamento também por consequências atrasadas e, dessa maneira, contribuir com o fortalecimento de repertórios individuais que favorecessem a sobrevivência de práticas culturais desejáveis. Desse modo, entende-se que há um outro sentido na aplicação do termo eficaz - o cultural.

Ao tratar de comportamento eficaz, Skinner refere-se, com frequência, a práticas relevantes para o convívio em grupo, nas quais o comportamento eficaz produz efeitos que são importantes a um só tempo para o grupo e para o indivíduo, como ilustrado na próxima asserção.

À medida que uma cultura produz máximas, leis, gramáticas e ciência, seus membros descobrem que é mais fácil comportar-se eficientemente [itálicos nossos] sem entrar em contato direto ou prolongado com as contingências de reforço assim formuladas (Skinner, 1969b, p. 141).
Tendo em conta as proposições skinnerianas a respeito das contingências culturais, pode-se concluir que, na visão skinneriana, repertório eficaz pode se referir aos comportamentos de um indivíduo, que produzem, a um só tempo, possibilidades de reforço para comportamentos do próprio indivíduo, enquanto originam condições que aumentem as chances de sobrevivência de práticas culturais relevantes. Dessa maneira, entende-se que segundo Skinner (1971/2002), na perspectiva cultural, ao contrário da perspectiva operante, a efetividade ou eficácia de um repertório comportamental individual está diretamente relacionada à produção de condições ambientais favoráveis ao grupo e não favorecedoras apenas do próprio indivíduo.

Essa noção de repertório eficaz não implica, necessariamente, negligenciar consequências reforçadoras para o indivíduo a favor da sobrevivência de práticas culturais, mas sugere que contingências operantes devam ser planejadas para que também sejam produzidas condições que venham a contribuir com práticas culturais desejáveis. Na concepção de Skinner (1987a), as contingências que modelam e fortalecem o repertório do indivíduo podem ser planejadas de maneira que produzam, a um só tempo, modificações ambientais que também auxiliem no estabelecimento e na manutenção de práticas culturais.

Do exposto até aqui esperamos ter explicitado que o favorecimento da sobrevivência de práticas culturais refere-se a um terceiro critério relativo ao sentido skinneriano de comportamento eficaz. Esse é, em nosso entendimento, o critério mais importante para Skinner. Esta interpretação parece plausível tendo em conta tanto aspectos gerais do texto skinneriano, quanto o fato dele ter elegido o bem das culturas como valor principal da ação humana, conforme pontuado por Castro e de Rose (2008) e por Dittrich e Abib (2004). Com a explicitação do critério cultural, completamos nossa análise a respeito do uso skinneriano da expressão comportamento eficaz.

A importância atribuída por Skinner ao comportamento eficaz fica patente, como já foi dito, em suas análises que tratam principalmente da necessidade de planejar contingências. Ele ressalta que a Análise do Comportamento deve ser aplicada com o objetivo de favorecer a aprendizagem de repertório eficaz. Seguem alguns dos argumentos empregados por ele na defesa do planejamento de contingências para favorecer a ocorrência de repertórios mais eficazes. 


\section{Repertório eficaz e planejamento de contingências}

Um caminho para se prevenir os danos, em longo prazo, que inter-relações reforçadoras podem produzir, é o planejamento de contingências para se ensinar repertórios mais eficazes. Skinner (1971/2002; 1972/ 1975d) argumenta que repertórios mais eficazes podem ser modelados naturalmente, porém ressalta que os processos naturais não garantem sua ocorrência. Complementando, Skinner (1987b) afirma que o processo de seleção do comportamento pelas consequências não apresenta direcionalidade e, por isso, não há orientação no tipo de comportamento selecionado. Isto porque os princípios comportamentais que orientam a seleção não escolhem a qualidade do comportamento a ser selecionado. Em vista disso, considera-se que tanto repertórios mais eficazes quanto menos eficazes possam ser modelados ao longo da história de relação do indivíduo com o ambiente.

Skinner (1987a) enfatiza que pelo fato do organismo responder muito mais rápido às consequências imediatas do comportamento do que às consequências culturais, a ação natural dos processos de seleção do comportamento tende a intensificar a aquisição de repertórios individuais que não favorecem, necessariamente, a sobrevivência de práticas culturais desejáveis. Desse modo, repertórios culturalmente mais eficazes podem ser mais difíceis de serem modelados naturalmente.

Para complementar, Skinner (1989a) ressalta que, devido aos limites acima descritos dos processos seletivos, geralmente, as principais consequências reforçadoras para práticas culturais são artificiais. Sobre isso ele afirma:

As principais consequências reforçadoras do ágape ${ }^{l}$ são, de fato artificiais. Elas são inventadas por nossa cultura, sobretudo porque justamente o tipo de coisa que fazemos nessas circunstâncias ajuda a cultura a resolver seus problemas e sobreviver (Skinner, 1989a, pp. 6-7).

Verifica-se nessa citação a preocupação do autor em esclarecer que, para sobreviver, práticas culturais devem tornar-se importantes para os indivíduos que as compartilham, pois, em caso contrário, não serão selecionadas. Somente as práticas culturais significativas (que produzem reforçadores) para os membros do grupo apresentam maiores possibilidades de sobreviver. Talvez por isso, Skinner (1987a) lembra que, mesmo apresentando importância para o grupo, muitas práticas culturais desejáveis podem ser extintas. Isto porque a imediaticidade com que ocorrem conse- quências operantes (reforçadoras) pode interferir negativamente na manutenção das práticas culturais. $\mathrm{Ou}$ seja, repertórios que não favorecem práticas culturais desejáveis são fortalecidos em um período menor de tempo e podem competir com a seleção de repertórios que seriam mais eficazes em fortalecer ou manter tais práticas. Usar embalagens e vasilhames reutilizáveis (não descartáveis) que produziam muito menos lixo, ou fazer "plantio direto", sem arar o solo e, assim, não produzindo erosão, são exemplos de práticas culturais desejáveis que foram abandonadas ou parcialmente substituídas por outras mais imediatistas e destrutivas. Abandonar o hábito saudável de comer "arroz com feijão", substituindo-os pelos "lanches", é outro exemplo que já vem ocorrendo entre os brasileiros. Não é por acaso, que governantes têm tentado recuperar ou fortalecer algumas dessas práticas com políticas públicas. Políticas desse tipo poderiam ser entendidas como tentativas de planejamento de contingências culturais.

Ainda, na mesma linha de argumentação, Skinner (1972/1975d) afirma que os conhecimentos produzidos pela Análise Experimental do Comportamento, já permitem o desenvolvimento de uma tecnologia comportamental apropriada ao "ensino" de repertório comportamental mais eficaz. Repertório que produza consequências reforçadoras para o indivíduo sem que estas consequências venham a ser incompatíveis com a manutenção de práticas culturais desejáveis. Continuando, Skinner (1972/1975d; 1971/2002) argumenta que a tecnologia comportamental seria um modo de se evitar acidentes de percurso que podem ocorrer, quando reforçadores trazem prejuízos, em longo prazo, tanto para o indivíduo quanto para as práticas culturais. Com conhecimento científico e planejamento, seria possível, nas palavras do próprio autor, maximizar as consequências das contingências que pudessem vir a produzir repertórios culturais mais eficazes.

O que é tecnologicamente útil no condicionamento operante é nosso crescente conhecimento da sutileza e complexidade das propriedades do comportamento, que podem ser delineadas até as características sutis e complexas das contingências de reforço que prevalecem no ambiente (Skinner, 1972/1975a, p. 61).

Nenhum sistema garante comportamento apropriado. É necessário que programas adequados tornem eficazes as contingências (Skinner, 1972/1975a, p. 65).

Nesse cenário, parece que para Skinner o planejamento de contingências é uma decorrência direta da sua concepção de repertório eficaz. 


\section{CONSIDERAÇÕES FINAIS}

$\mathrm{O}$ exame direto dos textos selecionados permitiu-nos explicitar alguns dos sentidos, ou dos critérios, com os quais Skinner emprega a expressão comportamento eficaz. Os critérios são compatíveis com o modelo de variação e seleção por consequências. Nossa análise permitiu explicitar critérios no plano ontogenético e no plano cultural; não encontramos, nos textos examinados, o emprego significativo da expressão estudada no plano filogenético. No domínio ontogenético, tendo em vista as chances de reforço, verificamos que o adjetivo eficaz pode referir-se a uma resposta operante, a uma classe de respostas, a um repertório comportamental e, ainda, a uma pessoa eficaz. Entretanto, em linhas gerais, dois sentidos de comportamento eficaz nos pareceram mais básicos no plano ontogenético: o de "classes de resposta" e o de "repertório".

Em resumo, no estudo aqui apresenado foram explicitados três significativos critérios, relativos ao emprego skinneriano do adjetivo eficaz para qualificar comportamentos. Ou seja, o autor pode referir-se: a) a uma classe de respostas com alta probabilidade de produzir reforçadores; b) a um repertório comportamental no qual muitas classes de resposta apresentam chances de produzir reforçadores e que, além disso, inclui certas classes de resposta que aumentam, indiretamente, as chances de outras classes produzirem reforçadores para o próprio indivíduo, e c) ao comportamento cultural (ou repertório cultural) que se define por promover o bem ou a sobrevivência das culturas e, com isso, promover o bem de gerações futuras. E, por fim, verificamos que tendo em vista dificuldades para a promoção de práticas culturais desejáveis, especialmente as dificuldades derivadas da sensibilidade às consequências imediatas, Skinner sugere recorrer-se ao uso de tecnologia comportamental para promover repertório culturalmente eficaz.

Do exposto, pode-se notar que todos os critérios mostram que a eficácia do comportamento se define por sua função. Ou seja, diferentes operantes, repertórios e comportamentos culturais podem mostrar-se eficazes, dependendo de seu efeito, de suas consequências. Mas esta observação pode ir um pouco mais longe; podemos sugerir que na sua concepção de comportamento eficaz, Skinner adota o critério de verdade do pragmatismo. Parece ser isto que Castro e de Rose (2008) querem dizer ao afirmarem que "as verdades, no behaviorismo radical, são funcionais: não há certo e errado, mas o que é efetivo e o que é inefetivo. E o bem, por sua vez, também é funcional, por- tanto relativo, da mesma forma como o é o conceito de reforçador" (p. 114). O critério de verdade como trabalho ou ação bem-sucedida (successful working) tem sido um postulado comum a diferentes modalidades de pragmatismo e de contextualismo (Abib, 2001; Baum, 1999; Guilhardi, 1995; Hayes \& Cols, 1993; Lattal \& Laipple, 2003; Tourinho \& Neno, 2003).

Outra constatação diz respeito à concepção do comportamento como ação. Pode-se verificar que, em todos os sentidos descritos neste estudo, comportamento eficaz, pode ser identificado com ação eficaz, com a ação prática que produz mudanças no ambiente ou no mundo. É o caso das classes de respostas que produzem suas próprias consequências reforçadoras; dos repertórios capazes de mudar os ambientes inclusive para maximizar suas chances de obter reforçadores e dos repertórios culturais capazes de trabalhar para a sobrevivência das culturas ou para o bem de outras gerações. O fato é que o qualificativo eficaz, em todos os critérios descritos, parece remeter, de alguma forma, à noção de que comportamento é ação, mas ação eficaz. Nossas observações parecem ir de encontro com as afirmações de Abib (2001) e de Lattal e Laipple (2003) de que o behaviorismo skinnerino pode ser vinculado à filosofia da ação jamesiana. Alguns fundamentos importantes tanto da noção funcional de verdade, mencionada no parágrafo anterior, quanto da filosofia da ação aqui referida, podem ser encontrados em James (1907/2005).

Por fim, os critérios aqui descritos para comportamento eficaz ainda podem nos remeter a rápidas considerações sobre o sistema ético skinneriano. No ponto de vista de Castro e de Rose (2008) "ética é entendida [...] por um valor ou conjunto de valores em relação ao qual justificamos determinadas ações, norteamos nossa conduta, decidimos o que é o melhor a ser feito dentre os vários caminhos possíveis" (p. 82). O sistema ético skinerianno está intimamente relacionado com o modelo de seleção do comportamento por consequências; os valores (bens) são definidos por dois tipos de efeitos das consequências: o efeito fortalecedor sobre o comportamento e os sentimentos que acompanham o fortalecimento. Com base nesses efeitos Skinner inferiu três tipos de bens que, em linhas gerais, seriam os seguintes: os bens pessoais, que são os reforçadores positivos para a própria pessoa; os bens dos outros, são os reforçadores positivos para os outros e os bens culturais que são as consequências de práticas culturais que promovem a sobrevivência de uma cultura (Castro \& de Rose, 2008; Dittrich \& Abib, 2004). 
Se nos voltarmos para os critérios que explicitamos, podemos supor uma relação entre o que o autor denominou comportamento eficaz com os valores que ele definiu, particularmente com os bens pessoais e com os bens culturais. No entanto, antes de uma conclusão desse tipo é preciso lembrar que, nos textos skinnerianos, pode-se encontrar duas formas de tratar o comportamento ético: uma descritiva e outra prescritiva (Castro \& de Rose, 2008; Dittrich \& Abib, 2004). Esses autores denominam descritivas, as sentenças relativas apenas às tentativas de explicar $o$ comportamento ético; e prescritivas, as exortações de Skinner para a promoção de determinados comportamentos. Isto posto, poderíamos, de maneira muito simplificada, concluir que ao menos o critério para definir repertório culturalmente eficaz poderia vincular-se com as prescrições de Skinner, uma vez que ele elegeu o bem das culturas como o principal valor que deveria nortear o planejamento cultural. Contudo, seria difícil afirmar se os demais critérios para comportamento eficaz, que se definem por chances de reforço, se relacionariam apenas com as descrições de Skinner e não com as suas prescrições. Essa dificuldade é justificada por Castro e de Rose (2008) quando eles afirmam haver uma "tensão" no behaviorismo radical entre descrição e prescrição, ou seja, mesmo quando Skinner tenta demonstrar que está descrevendo, muitas vezes, nas entrelinhas, ele parece estar exortando.

Para concluir, gostaríamos de enfatizar que nossa pretensão com este ensaio foi, antes de tudo, contribuir com estudos dos textos skinnerianos, explicitando alguns dos sentidos com os quais Skinner emprega a expressão comportamento eficaz. Apenas a título de sugestão, tecemos algumas rápidas considerações a respeito de contribuições que nosso estudo pode vir a oferecer, aos que se interessam em estudar o sistema teórico skinneriano na perspectiva do pragmatismo e da ética.

\section{REFERÊNCIAS}

Abib, J. A. D. (2001). Behaviorismo radical como pragmatismo na epistemologia. Em H. Guilhardi, M. B. Madi, P. P. Queiroz \& M. C. Scoz. (Orgs.), Sobre comportamento e cognição: Vol. 8. Expondo a variabilidade (pp. 158-161). Santo André: Esetec.

Abib, J. A. D. (2007). Comportamento e sensibilidade: Vida, prazer e ética. Santo André: Esetec.

Baum, W. M. (1999). Compreender o behaviorismo: Ciência, comportamento e cultura (M. T. A. Silva; M. A. Matos \& G. Y. Tomanari, Trads.). Porto Alegre: Artmed.

Carrara K. (2000). Contextualismo, contracontrole e cidadania. Revista da APG/PUCSP, 9(21), 23-38.
Carrara, K. (2001). Implicações do contextualismo pepperiano no behaviorismo: Alcance e limitações. Em H. Guilhardi \& N. C. Aguirre (Orgs.), Sobre comportamento e cognição: Vol. 17. Expondo a variabilidade (pp. 327-333). Santo André: Esetec.

Castro, M. S. L. B., \& de Rose, J. C. C. (2008). A ética skinneriana e a tensão entre descrição e prescrição no behaviorismo radical. Santo André: Esetec.

Catania, C. A. (1999). Aprendizagem: Comportamento, linguagem e cognição (D. G. Souza, Trad). Porto Alegre: Artes Médicas Sul.

Dittrich, A., \& Abib, J. A. D. (2004). O sistema ético skinneriano e consequências para a prática dos analistas do comportamento. Psicologia: Reflexão e Crítica, 17(3), 427-433.

Guilhardi, H. J. (1995). Um modelo comportamental de análise de sonhos. Em B. Range (Org.), Psicoterapia comportamental e cognitiva de transtornos psiquiátricos (pp. 257-266). Campinas: Editorial Psy.

Hayes, S. C., Hayes, L. W., Reese, H. W., \& Sarbin, T. R. (1993). Varieties of scientific contextualism. Reno: Context Press.

Holland, J. G. (1978). Behaviorism: Part of the problem or part of the solution? Journal of Applied Bevavior Analysis, 11, 163174.

James, W. (2005). Pragmatismo (J. C. Silva, Trad.). São Paulo: Martin Claret. (Original publicado em 1907)

Lattal, K. A., \& Laipple, J. S. (2003). Pragmatism and behavior. Em K. A. Lattal \& P. N. Chase (Orgs.), Behavior theory and philosophy (pp. 41-61). New York: Klumer Academic/ Plenum Publishers.

Lopes, C. E. (2007). O conceito de estímulo no behaviorismo radical: Esboço de uma interpretação pragmatista. Em W. C. M. P. Silva (Org.), Sobre comportamento e cognição: Vol. 20. Reflexões teórico-conceituais e implicações para pesquisa (pp. 234-242). Santo André: Esetec.

Michael, J. (1977). Radical behaviorism as a way of life. Em J. E. Krapfl \& E. A. Vargas (Orgs.), Behaviorism and ethics (pp. 293-303). Kalanazoo, MI: Behaviordelia.

Millenson, J. R. (1975). Princípios de análise do comportamento (A. A. Souza \& D. Rezende, Trads.). Brasília: Coordenada. (Original publicado em 1967)

Morris, E. (1988). Contextualism: The world view of behavior analysis. Journal of Experimental Child Psychology, 46, 289323.

Skinner, B. F. (1957). Verbal behavior. New York: ApplentonCentury-Crofts.

Skinner, B. F. (1969a). Utopia as an experimental culture. Contingencies of reinforcement: A theoretical analysis (pp. 29-49). New York: Englewood Cliffs.

Skinner, B. F. (1969b). An operant analysis of problem solving. Contingencies of reinforcement: A theoretical analysis (pp. 133-157). New York: Englewood Cliffs.

Skinner, B. F. (1974). About behaviorism (pp. 148-166). New York: Alfred A. Knopf.

Skinner, B. F. (1975a). A tecnologia do ensino. Em B. F. Skinner (Org.), Tecnologia do ensino (pp. 57-88) (R. Azzi, Trad.). São Paulo: EPU. (Original publicado em 1972) 
Skinner, B. F. (1975b). Ensinar a pensar. Em B. F. Skinner (Org.), Tecnologia do ensino (pp. 109-136) (R. Azzi, Trad.). São Paulo: EPU. (Original publicado em 1972)

Skinner, B. F. (1975c). A motivação do estudante. Em B. F. Skinner (Org.) Tecnologia do ensino (pp. 137-158) (R. Azzi, Trad.). São Paulo: EPU. (Original publicado em 1972)

Skinner, B. F. (1975d). Uma revisão do ensino. Em B. F. Skinner (Org.), Tecnologia do ensino (pp. 189-215) (R. Azzi. Trad.). São Paulo: EPU. (Original publicado em 1972)

Skinner, B. F. (1975e). Walden II: Uma sociedade do futuro (R. Moreno \& N. R. Saraiva. Trads.). São Paulo: EPU. (Original publicado em 1948)

Skinner, B. F. (1987a). What is wrong with daily life in the western world. Em B. F. Skinner (Org.), Upon further reflection (pp. 15-32). New Jersey: Prentice-Hall.

Skinner, B. F. (1987b). Selection by consequences. Em B. F. Skinner (Org.), Upon further reflection (pp. 51-63). New Jersey: Prentice-Hall.

Skinner, B. F. (1989a). The place of feeling in the analysis of behavior. Em B. F. Skinner (Org.), Recent issues in the analysis of behavior (pp. 3-11). Columbus: Merrill.

Skinner, B. F. (1989b). Genes and behavior. Em B. F. Skinner (Org.), Recent issues in the analysis of behavior (pp. 49-56). Columbus: Merrill.
Skinner, B. F. (1989c). The operant side of behavior therapy. Em B. F. Skinner (Org.), Recent issues in the analysis of behavior (pp. 73-84). Columbus: Merrill.

Skinner, B. F. (1989d). The initiating self. Em B. F. Skinner (Org.), Recent issues in the analysis of behavior (pp. 27-33). Columbus: Merrill.

Skinner, B. F. (1998). Ciência e comportamento humano (J. C. Todorov \& R. Azzi. Trads.). São Paulo: Martins Fontes. (Original publicado em 1953)

Skinner, B. F. (2002). Beyond freedom and dignity. Indianapolis: Hackett. (Original publicado em 1971)

Tourinho, E. Z., \& Neno, S. (2003). Effetiveness as truth criterion in behavior analysis. Behavior philosophy, 31, 63-80.

Zuriff, G. E. (1985). Behavioral epistemology. Em G. E. Zuriff (Org.), Behaviorism: A conceptual reconstruction (pp. 250278). New York: Columbia University Press.

Recebido: $16 / 09 / 2008$ Última revisão: 18/05/2009 Aceite final: 27/09/2009

\section{Nota:}

${ }^{1}$ Skinner (1989b) esclarece que ágape refere-se a uma terminologia grega empregada por ele para a compreensão do efeito de contingências culturais.

\section{Sobre as autoras:}

Ieda Maria Bertola Mazzo: Mestre em Análise do Comportamento pela Universidade Estadual de Londrina

Maura Alves Nunes Gongora: Docente da Universidade Estadual de Londrina. Doutora em Psicologia Clínica pela USP. Pós-doutora em Fundamentos do Behaviorismo Radical pela UFSCar.

Endereço para correspondência: maura@uel.br 